\title{
Pessoas Vivendo com HIV/AIDS: Enfrentamento, Suporte Social e Qualidade de Vida
}

\author{
Eliane Maria Fleury Seidl 12 \\ Célia Maria Lana da Costa Zannon \\ Bartholomeu Torres Tróccoli \\ Universidade de Brasilia
}

\begin{abstract}
Resumo
A pesquisa testou modelo sobre as relações entre qualidade de vida (QV), condição clínica, escolaridade, situação conjugal, enfrentamento e suporte social, em pessoas portadoras do HIV/AIDS. Participaram 241 pessoas (161 homens), de 20 a 64 anos, 169 sintomáticas e 72 assintomáticas, 208 delas em uso de terapia anti-retroviral. A variável critério QV foi investigada nas dimensões psicossocial, física, do ambiente e qualidade de vida geral, mediante análises de regressão múltipla hierárquica. Suporte social emocional, enfrentamento focalizado na emoção, enfrentamento focalizado no problema e viver com parceiro(a) foram preditores significativos da dimensão psicossocial da QV, alcançando a maior variância explicada ( $59 \%$ ajustado). Suporte social emocional e enfrentamento focalizado na emoção foram preditores significativos nas análises relativas às demais dimensões da QV. Discutem-se implicações para as práticas de saúde referentes às ações profissionais propiciadoras do bem-estar psicológico e da qualidade de vida em pessoas vivendo com HIV/AIDS.

Palavras-chave: HIV/AIDS; qualidade de vida; enfrentamento; suporte social; WHOQol-100.
\end{abstract}

\section{Persons Living with HIV/AIDS: Coping, Social Support and Quality of Life}

\begin{abstract}
A model describing quality of life (QoL) as a function of health conditions, education, marital status, coping and social support in symptomatic or asymptomatic HIV-infected patients was tested. The participants were 241 adults, aged 20 to 64, 161 men, 169 symptomatic, and 208 on antiretroviral treatment. The criterion variable QoL was represented by the psychosocial, physical, environmental and overall quality of life dimensions measured by the Brazilian version of the World Health Organization QoL Assessment. Hierarchical multiple regression analysis revealed that the emotional support, emotion-focused coping, problem-focused coping, and marital status were significant predictors explaining $59 \%$ (adjusted) of the variance in the psychosocial dimension. Emotional support and emotion-focused coping were significant predictors associated to the other QoL analyzed dimensions. Implications concerning professional interventions and factors that should contribute to the improvement of the psychological well-being and QoL of seropositive persons are discussed.

Keywords: HIV/AIDS; coping; social support; quality of life, WHOQoL-100.
\end{abstract}

Desde o aparecimento dos primeiros casos e a identificação do vírus da imunodeficiência humana (HIV), a Síndrome da Imunodeficiência Adquirida (AIDS) constitui um dos grandes problemas de saúde pública no plano mundial. O Ministério da Saúde do Brasil informa a existência de 310.300 casos de AIDS notificados, no período de 1980 a dezembro de 2003 (Ministério da Saúde, 2003).

Os indicadores de mortalidade por AIDS sofreram alterações acentuadas com o advento da terapia anti-retroviral combinada, particularmente nos países em que a disponibilidade desses medicamentos é universal e gratuíta, como no Brasil. Ainda sem cura, a AIDS hoje tem tratamento e traz novos desafios para as pessoas infectadas pelo HIV. A vivência da sexualidade, da conjugalidade, da paternidade/maternidade com parceiros com sorologia igual ou diferente, o enfrentamento à luz das possibilidades de tratamento e o fortalecimento da rede social de apoio são algumas das novas questões de natureza psicossocial vivenciadas por pessoas soropositivas (Rabkin, Ferrando, Lin, Sewell \& McElhiney, 2000).

\footnotetext{
${ }^{1}$ A pesquisa refere-se à Tese de Doutorado da primeira autora, defendida junto ao Instituto de Psicologia da Universidade de Brasília, sob orientação da segunda autora e co-orientação do terceiro autor.

${ }^{2}$ Endereço para correspondência: Universidade de Brasília, Instituto de Psicologia, Campus Darcy Ribeiro, Brasília, DF, 70910 900. Fone: (61) 3072625 (Ramal 405). E-mail:seidl@unb.br
}

Nessa perspectiva, o construto qualidade de vida (QV) vem suscitando grande interesse, consoante com os novos paradigmas que têm norteado as práticas em saúde (Seidl \& Zannon, 2004; The WHOQOL Group, 1998). Estudos sobre QV na área do HIV/AIDS podem ser divididos em dois grupos. $\mathrm{O}$ primeiro inclui trabalhos realizados em momento anterior às possibilidades efetivas de tratamento, quando o agravamento do quadro clínico caracterizado pelo aparecimento dos sintomas da AIDS motivava a investigação de variáveis físicas, como dor e fadiga (Rosenfeld \& cols., 1996). O segundo grupo inclui estudos realizados após o advento da terapia anti-retroviral combinada, valorizando variáveis de natureza psicossocial em face da possibilidade de se conviver com a condição por muitos anos, devido ao caráter crônico da enfermidade (Barroso, 1997; Smith, Avis, Mayer \& Swislow, 1997; Wu, 2000).

Como a soropositividade pode implicar grande variabilidade da condição clínica, uma tendência clara dos estudos sobre QV tem sido a comparação entre pessoas assintomáticas e aquelas sintomáticas/doentes de AIDS. Os achados indicam que as segundas apresentam piores escores de avaliação da QV, bem como do funcionamento físico e psicológico (Revicki, Sorensen \& Wu, 1998). Cunningham e colaboradores (1995), por sua vez, verificaram que pessoas soropositivas pobres obtiveram médias significativamente mais baixas em vários dos indicadores avaliados, como qualidade de vida geral, bem-estar emocional, funcionamento cognitivo e funcionamento social. Esses resultados apontam para as dificuldades 
das pessoas que, além da condição de enfermidade, lidam com carências sociais e econômicas que seguramente têm impacto na QV.

A partir de meados dos anos 1990, os estudos passaram a investigar associações entre variáveis psicológicas - enfrentamento e suporte social - e a percepção da QV, buscando identificar fatores que propiciam o ajustamento à condição de enfermidade crônica e enfrentamento ativo diante da disponibilidade de tratamento (Dunbar, Mueller, Medina \& Wolf, 1998). Friedland, Renwick e McColl (1996) investigaram as variáveis suporte social, estratégias de enfrentamento, renda, idade, emprego e a severidade dos sintomas como preditores da QV em pessoas vivendo com HIV/ AIDS. Mediante análises de regressão hierárquica, os pesquisadores verificaram que renda familiar, suporte social emocional e enfrentamento focalizado no problema foram preditores positivos da QV, enquanto o enfrentamento focalizado na emoção foi um preditor negativo, explicando, juntos, 48,3\% da variância da variável critério. A investigação sobre o suporte social tem sido objeto de interesse devido às situações de preconceito e discriminação que podem caracterizar as reações sociais à soropositividade, levando, muitas vezes, ao isolamento social, à restrição dos relacionamentos interpessoais e às dificuldades no campo afetivo-sexual, com impacto negativo na rede social de apoio de pessoas que vivem com HIV/ AIDS (Green, 1993). Evidencia-se, com alguma consistência, a associação entre disponibilidade e satisfação com o suporte social, bem-estar psicológico e percepção positiva da qualidade de vida, corroborando achados que indicam o papel do apoio social como moderador do estresse em contextos relacionados ao processo saúdedoença (Leserman \& cols., 2000; Schmitz \& Crystal, 2000).

A escassez de estudos sobre QV em pessoas vivendo com HIV/AIDS no Brasil motivou a realização da presente pesquisa, que teve como objetivo principal testar um modelo sobre as relações entre qualidade de vida, condição clínica, escolaridade, situação conjugal, enfrentamento e suporte social, em pessoas soropositivas. No modelo, proposto a partir de achados da literatura e da experiência da primeira autora em serviço de saúde voltado para o atendimento a essa clientela, algumas relações entre variáveis eram esperadas. Presumia-se que a QV de pessoas soropositivas, assintomáticas ou sintomáticas, com diferentes níveis de escolaridade, vivendo ou não com parceiro(a), pudesse ser predita em função das estratégias de enfrentamento e do suporte social percebido, e que essas variáveis psicológicas explicassem uma quantidade significativa da variância da QV, uma vez controlada a influência das variáveis condição clínica, escolaridade e situação conjugal. Esperava-se que a disponibilidade e a satisfação com o suporte emocional e o suporte instrumental fossem fortes preditores da QV, assim como as estratégias de enfrentamento focalizadas no problema (cf. Friedland \& cols., 1996; Schmitz \& Crystal, 2000). No que concerne à condição clínica, esperava-se que pessoas sintomáticas apresentassem piores escores nas medidas de QV, notadamente na dimensão física (Revicki \& cols., 1997). Presumindo que a escolaridade fosse indicador indireto da situação socioeconômica, esperava-se que níveis mais baixos de escolaridade estivessem associados a piores escores nas medidas de QV, em especial a dimensão do ambiente (Cunningham \& cols., 1995).

\section{Método}

\section{Participantes \\ Caracterização sociodemográfica}

A amostra foi composta de 241 pacientes soropositivos, 161 $(66,8 \%)$ do sexo masculino, que estavam em acompanhamento ambulatorial em dois serviços públicos de referência para tratamento de HIV/AIDS no Distrito Federal - o Hospital Universitário de Brasília e a Unidade Mista da Secretaria de Saúde do DF - que contabilizavam, no total, cerca de 1000 pacientes HIV+ cadastrados. A idade variou de 20 a 64 anos $(m=37,4$; $d p=7,8)$. A distribuição da amostra quanto à escolaridade indicou que 33,6\% tinham até o ensino fundamental completo, 35,7\% estudaram até o ensino médio completo, 12,9\% tinham o curso superior incompleto e $17,8 \%$ o superior completo.

Quanto à situação conjugal, 41,9\% dos participantes estavam casados ou vivendo em união consensual e mais da metade $(57,7 \%)$ não estava vivendo com parceiro(a), sendo solteiros, separados, divorciados ou viúvos. A maioria $(58,1 \%)$ referiu orientação heterossexual. Os percentuais de pessoas heterossexuais vivendo com ou sem parceiro(a) eram semelhantes; quanto às pessoas homossexuais e bissexuais, o maior percentual foi daquelas que não viviam com parceiro(a). No que se refere à situação empregatícia, 31,5\% dos participantes estavam empregados com direitos trabalhistas, $13,7 \%$ possuíam atividade autônoma regular, 12,9\% estavam desempregados e 19,5\% eram aposentados.

\section{Caracterização médico-clínica}

Setenta e duas pessoas (29,9\%) eram assintomáticas e 169 (70,1\%) eram sintomáticas/doentes de AIDS. O tempo de conhecimento do diagnóstico variou de 14 anos a menos de 1 ano $(m=4,1 ; d p=3,17)$. Os valores da contagem dos linfócitos T CD4+ (número de células por milímetro cúbico de sangue) variaram de 2 a 1328 ( $m=409,3$; $d p=277$ ), mostrando grande variabilidade entre os participantes quanto à integridade do sistema imunológico. A carga viral plasmática, medida pela quantidade de cópias virais por mililitro $(\mathrm{mL})$ de sangue periférico, variou de 80 cópias $/ \mathrm{mL}$ até 2.350 .000 cópias $/ \mathrm{mL}$ $(m=51694 ; d p=188069,7)$. Quase 1/3 (28,2\%) dos participantes estava com carga viral indetectável ( $=80$ cópias $/ \mathrm{mL}$ ), indicador de alta eficácia do tratamento anti-retroviral. Duzentos e oito participantes $(86,3 \%)$ relataram fazer uso de medicamentos anti-retrovirais (ARV), sendo que $93,5 \%$ dos pacientes sintomáticos estavam usando esses medicamentos. Entre os 72 pacientes assintomáticos, quase 2/3 $(69,4 \%)$ faziam uso da terapia anti-retroviral.

\section{Instrumentos}

- Questionário sociodemográfico: Com 7 questões: sexo, idade, escolaridade, situação conjugal, número de filhos, soropositividade na familia e situação empregatícia.

- Questionário médico-clínico: Composto de 10 questões: ano de conhecimento do diagnóstico; número de internações anteriores associadas ao HIV; presença de sintomas e/ou doenças infecciosas oportunistas anteriores ou atuais; uso de terapia anti-retroviral; interrupção por conta própria do uso de anti-retrovirais; auto- 
avaliação da adesão ao tratamento anti-retroviral e orientação sexual. Baseado nas respostas dadas a esse questionário, os pacientes foram classificados em uma das duas condições, conforme definição de Oliveira, Mello e Silva, Atomyla, Bonasser $F^{o}$ e Geraldes (1996): 1) assintomático ou portador do HIV, quando o paciente referia ainda não ter tido nenhum sinal ou sintoma referente à enfermidade; 2) sintomático ou doente de AIDS, quando o paciente referia ter tido pelo menos um dos sintomas relacionados à AIDS e/ou pelo menos uma infecção oportunista associada à síndrome. O questionário foi pré-testado em 10 pacientes, com condição sociodemográfica diversificada, para adequação quanto à linguagem e seqüência dos itens.

- Escala Modos de Enfrentamento de Problemas (EMEP): Instrumento derivado da escala de Vitaliano, Russo, Carr, Maiuro e Becker (1985), em versão adaptada para o português por Gimenes e Queiroz (1997) e submetido à análise fatorial por Seidl, Tróccoli e Zannon (2001), composto de 45 itens, distribuídos em 4 fatores: 1) enfrentamento focalizado no problema (18 itens, $\alpha=0,84)$, estratégias comportamentais que representam aproximação em relação ao estressor, voltadas para o seu manejo ou solução, bem como estratégias cognitivas direcionadas para a reavaliação e ressignificação do problema; 2) enfrentamento focalizado na emoção (15 itens, $\alpha=0,81$ ), estratégias cognitivas e comportamentais de esquiva e/ou negação, expressão de emoções negativas, pensamento fantasioso, autoculpa e/ou culpabilização de outros, com função paliativa ou de afastamento do problema; 3 ) busca de suporte social ( 5 itens, $\alpha=0,70$ ) procura de apoio social emocional ou instrumental para ajudar a lidar com o problema; 4) busca de práticas religiosas ( 7 itens, $\alpha=0,74$ ), pensamentos e comportamentos religiosos como modos de enfrentamento e manejo do estressor. As respostas foram dadas em escala Likert de 5 pontos ( $1=$ "nunca faço isso" a $5=$ "faço isso sempre"). Os escores foram obtidos pela média aritmética e quanto mais altos, maior a freqüência de utilização da estratégia de enfrentamento.

— Escala de Suporte Social para Pessoas Portadoras do HIV/AIDS: Versão brasileira do Social Support Inventory for People Who Are HIV Positive or Have AIDS (Renwick, Halpen, Rudman \& Friedland, 1999), a partir de adaptação e tradução para o português, com base em procedimentos de análise semântica e tradução reversa. A investigação da estrutura fatorial com a amostra de pessoas soropositivas, anterior às análises descritivas e multivariadas do presente estudo, resultou em dois fatores, semelhantes ao instrumento original: 1. suporte emocional (12 itens, $\alpha=0,92)$ - percepção e satisfação quanto à disponibilidade de escuta, atenção, informação, estima, companhia e apoio emocional em relação à soropositividade; 2. suporte instrumental (12 itens, $\alpha=0,84)$ - percepção e satisfação quanto à disponibilidade de apoio no manejo ou resolução de questões operacionais do tratamento ou do cuidado de saúde, de atividades práticas do cotidiano, de ajuda material e/ou financeira. Respostas foram dadas em escala Likert de 5 pontos, quanto à frequêencia e satisfação com os suportes. Escores mais altos indicaram relatos de maior disponibilidade percebida e satisfação com o suporte social. - Instrumento de Avaliação da Qualidade de Vida da Organização Mundial de Saúde (WHOQoL-100): Versão brasileira do instrumento completo (100 itens), validada por Fleck e colaboradores (1999), com base na estrutura fatorial de Power, Bullinger e Harper (1999), com as dimensões: 1) física, 28 itens, 7 facetas (atividades da vida diária; capacidade de trabalho; dependência de medicação ou de tratamento; dor e desconforto; energia e fadiga; mobilidade; sono e repouso); 2) psicológica, 24 itens, 6 facetas (aparência e auto-imagem; autoestima; espiritualidade, religião e crenças pessoais; pensamento, aprendizagem, memória e concentração; sentimentos negativos e sentimentos positivos); 3) relacionamento social, 12 itens, 3 facetas (atividade sexual; relações pessoais; suporte social); 4) ambiente, 32 itens, 8 facetas (ambiente do lar; ambiente físico; disponibilidade e qualidade de cuidados de saúde e sociais; oportunidades de adquirir novas informações e habilidades; acesso ou oportunidades de recreação e lazer; recursos financeiros; segurança física e proteção; transporte); e, 5) QV geral, escore oriundo das respostas a quatro itens (satisfação com a vida, satisfação com a saúde, avaliação e satisfação com a qualidade de vida). As escalas de respostas são do tipo Likert com 5 pontos e os escores foram obtidos pela média aritmética, para as facetas e dimensões, variando de 1 a 5 . Quanto à consistência interna, os valores alphas de Cronbach são superiores a 0,70 para as facetas e as dimensões (Fleck \& cols., 1999).

\section{Procedimento de coleta de dados}

Os participantes foram convidados em dias de consulta médica ou quando estavam realizando algum outro procedimento na unidade de saúde. A resposta aos instrumentos, após assinatura do Termo de Consentimento Livre e Esclarecido, ocorreu em dia e horário agendados, no serviço de saúde onde o paciente estava vinculado. A aplicação ocorreu em uma única sessão para a quase totalidade dos participantes e a maioria levou cerca de 80 minutos para responder aos instrumentos. Ocorreram menos de 10\% de recusas e desistências. Aplicação individual assistida foi utilizada para os questionários sociodemográfico e médico-clínico e para a Escala de Suporte Social para Pessoas Portadoras do HIV/AIDS. Para o WHOQoL-100 e a EMEP, foi utilizado procedimento de resposta sem a presença do pesquisador, após orientação sobre a forma de preenchimento.

\section{Análise do modelo}

Análises de regressão múltipla hierárquica foram utilizadas para verificar se estratégias de enfrentamento e suporte social possuíam relações preditivas significativas sobre as dimensões da QV, uma vez controlados os efeitos das variáveis condição clínica, escolaridade e situação conjugal. Para tanto, as oito variáveis preditoras foram introduzidas em três passos. A primeira variável na equação, condição clínica (assintomático versus sintomático) foi escolhida por representar uma característica de toda a amostra que poderia influenciar na percepção da QV, devido ao seu papel como estressor. No segundo passo, ingressaram em bloco as variáveis escolaridade e situação conjugal (viver com parceiro(a) versus viver sem parceiro(a), considerando sua relativa estabilidade como características sociodemográficas dos participantes, podendo afetar a relação da 
condição clínica com a QV. No último passo, foram introduzidas as variáveis psicológicas enfrentamento focalizado no problema, enfrentamento focalizado na emoção, busca de práticas religiosas, suporte social instrumental e suporte social emocional que entraram conjuntamente como terceiro bloco.

\section{Resultados}

Análises exploratórias de dados mostraram a adequação das variáveis quanto aos pressupostos exigidos para análises multivariadas. As freqüências das variáveis antecedentes e critério mostraram distribuições próximas à normalidade, considerando os indicadores de dispersão e de tendência central. Matrizes de correlação entre as variáveis mostraram ausência de singularidade e de multicolinearidade. Não foram encontrados casos extremos univariados e multivariados. Os dados faltosos identificados (inferior a $2 \%$ ) foram substituídos pela média do respectivo item.

\section{Análises fatoriais preliminares}

Para testar a estrutura empírica das medidas no que se refere à amostra específica, os resultados do WHOQoL-100 e da EMEP foram submetidas a análises fatoriais exploratórias (principal axis fatoring), conforme recomendado por Tabachnick e Fidell (1996). No caso da EMEP, com rotação oblíqua $(\mathrm{KMO}=0,79)$, a estrutura fatorial foi parcialmente confirmada. Observou-se a fusão do fator enfrentamento focalizado no problema com o fator busca de suporte social, optando-se pela manutenção da denominação enfrentamento focalizado no problema $(\alpha=0,83)$. Do ponto de vista teórico e empírico, esses resultados foram considerados plausíveis, pois se observa que busca de suporte social tem obtido correlação, de moderada a alta, com focalização no problema, chegando a ser considerado um componente dessa modalidade de enfrentamento por alguns estudiosos do construto (Clark, Bormann, Cropanzano $\&$ James, 1995). Os demais fatores enfrentamento focalizado na emoção $(\alpha=0,80)$ e busca de práticas religiosas $(\alpha=0,68)$ repetiram a estrutura encontrada por Seidl e colaboradores (2001). Verificou-se ainda a perda de poucos itens que obtiveram carga fatorial abaixo de 0,33 . Tendo em vista os bons indicadores psicométricos, optou-se por considerar os resultados dessa solução fatorial para a composição dos escores dos fatores da EMEP na análise de regressão hierárquica.

No caso do WHOQoL-100, a investigação fatorial exploratória, feita a partir dos escores obtidos pelos participantes nas 25 facetas, com rotação ortogonal $(\mathrm{KMO}=0,92)$, corroborou parcialmente a estrutura do instrumento. Constatou-se a fusão das seis facetas originais da dimensão psicológica com as três do relacionamento social, mais as facetas sono e repouso (dimensão física) e recreação e lazer (dimensão do ambiente). Em uma enfermidade ainda associada ao preconceito e à discriminação, considerou-se plausível que aspectos do relacionamento social pudessem estar associados à dimensão psicológica. Quanto à faceta recreação e lazer, a associação justificase pelo impacto que a presença ou a ausência de atividades de diversão e distração podem ter sobre o bem-estar psicológico. No que se refere à faceta sono e repouso, foi considerada sua função na reposição do desgaste físico e mental, especialmente em situações de estresse, bem como a associação entre problemas psicológicos e distúrbios do sono. Denominou-se essa nova dimensão de psicossocial (11 facetas, $\alpha=0,89)$. As demais dimensões não sofreram modificações relevantes em sua composição: dimensão do ambiente $(\alpha=0,82)$, dimensão física $(\alpha=0,80)$ e QV geral $(\alpha=0,70)$. As cargas fatoriais das facetas variaram de 0,86 a 0,35 e nenhuma delas foi excluída. Considerando os bons indicadores psicométricos encontrados e a necessidade de valorizar o dado empírico devido às especificidades da amostra estudada, optou-se por considerar essa solução fatorial da WHOQoL-100 nas análises de regressão hierárquica, seguindo procedimentos recomendados na utilização de técnicas multivariadas (Tabachnick \& Fidell, 1996).

\section{Características da amostra quanto ao suporte social, enfrentamento e qualidade de vida}

Os resultados revelaram a diversidade da amostra quanto às medidas das estratégias de enfrentamento, do suporte social e da QV. Quanto ao suporte social, os indicadores e a distribuição dos escores referentes ao suporte emocional $(m=3,85 ; d p=0,79)$ e instrumental $(m=3,62 ; d p=0,76)$, com assimetria levemente à direita, indicaram que a maior parte dos participantes relatou disponibilidade e satisfação com essas modalidades de apoio. Verificou-se ainda associação positiva significativa entre as duas modalidades de suporte social $(r=0,57 ; p<0,001)$. Investigou-se a associação do suporte social com escolaridade, situação conjugal e condição clínica. Análises de variância indicaram diferenças significativas quanto à escolaridade e à situação conjugal em relação ao suporte emocional: pessoas com escolaridade mais alta $(F(1,239)=7,53 ; p<0,001)$ ou que viviam com parceiro(a) $(F(1,239)=8,18 ; p<0,001)$ apresentaram médias mais elevadas nessa modalidade de suporte. Quanto ao suporte instrumental, verificou-se diferença significativa apenas em relação à situação conjugal, com a média mais alta das pessoas que viviam com parceiro(a) $(F(1,239)=14,89 ; p<0,001)$. Não foram observadas diferenças nas médias das duas modalidades de suporte segundo a condição clínica.

As médias do enfrentamento focalizado no problema $(m=3,47$; $d p=0,68)$ e da busca de prática religiosa $(m=3,61 ; d p=0,90)$ foram mais altas, indicando maior utilização dessas duas estratégias. Os resultados do enfrentamento focalizado na emoção $(m=2,17 ; d p=0,66)$ mostraram sua utilização em menor freqüência. Análises de variância não indicaram diferenças entre as médias dos escores do enfrentamento focalizado no problema segundo a escolaridade, a situação conjugal e a condição clínica. No que concerne à estratégia focalizada na emoção e à busca de práticas religiosas, observou-se diferença entre as médias segundo a escolaridade: pessoas com menos escolaridade apresentaram médias mais altas, indicando uso mais freqüente de enfrentamento na emoção $(F(1,239)=11,12 ; p<0,001)$ e de busca de práticas religiosas $(F(1,239)=5,41 ; p<0,01)$. Não se observaram diferenças entre pessoas assintomáticas e sintomáticas quanto às médias das três modalidades de enfrentamento.

No que se refere às dimensões da QV, os indicadores mostraram distribuição semelhante das dimensões psicossocial $(m=3,58$; 
$d p=0,58)$, física $(m=3,54 ; d p=0,59)$ e QV geral $(m=3,55 ; d p=0,76)$. A dimensão do ambiente apresentou a média mais baixa $(m=3,32$; $d p=0,52)$, o que é um indicador de maior insatisfação e avaliação desfavorável dessa dimensão no conjunto da amostra estudada. Nos dados descritivos sobre as facetas, destaca-se as cinco áreas que apresentaram escores mais baixos, indicativos de maiores dificuldades e insatisfação: sentimentos negativos $(m=3,15 ; d p=0,85)$, atividade sexual $(m=3,13 ; \not p=1,01)$, dependência de medicação e tratamento $(m=2,57 ; \not p=0,90)$, segurança física e proteção $(m=2,97 ; \not p=0,59) \mathrm{e}$ recursos financeiros $(m=2,77 ; d p=0,79)$.

\section{Os testes do modelo}

O resultado da regressão múltipla hierárquica onde a dimensão psicossocial foi a variável critério mostrou que, no primeiro passo, os valores de beta e de $\mathrm{R}$ foram próximos a zero. No segundo passo, a introdução da escolaridade e da situação conjugal incrementou os valores de $R^{2} \mathrm{em} 8 \%$, com essas variáveis contribuindo para a explicação da variância da dimensão psicossocial, que alcançou 9\%. Após a entrada de todas as variáveis na equação, observou-se um incremento significativo de $\mathrm{R}^{2}$, da ordem de $52 \%$. O modelo final (Tabela 1), com $59 \%$ (ajustado) de variância explicada, apresentou quatro variáveis significativas: suporte emocional, como o mais forte preditor, enfrentamento focalizado na emoção (preditor negativo), enfrentamento focalizado no problema e situação conjugal (vivendo com parceiro/a). No teste da dimensão física como variável critério, a condição clínica $(\beta=0,16 ; p<0,05)$, introduzida no primeiro passo, contribuiu sozinha para o modelo, alcançando $3 \%$ de variância explicada. A adição do segundo bloco de variáveis resultou em incremento significativo na variância explicada, equivalente a $8 \%$. No terceiro passo, constatou-se um aumento importante da variância explicada da dimensão física, da ordem de $16 \%$. O modelo final (Tabela 1) apresentou duas variáveis significativas responsáveis por $22 \%$ (ajustado) da explicação da variância da dimensão física: enfrentamento na emoção (preditor negativo) e condição clínica (assintomático).

No teste em que a dimensão do ambiente foi a variável critério, a condição clínica não alcançou significância ao entrar sozinha no primeiro passo. No segundo passo, houve um incremento importante da variância explicada, que chegou a 19\%, com as variáveis escolaridade e situação conjugal contribuindo de modo significativo para o modelo. A introdução de todas as variáveis na equação mostrou um aumento de $R^{2}$ da ordem de $27 \%$. O modelo final (Tabela 2) apresentou quatro variáveis significativas: escolaridade, mais forte preditor, suporte instrumental, enfrentamento focalizado na emoção (preditor negativo) e suporte emocional. As quatro variáveis explicaram $45 \%$ (ajustado) da variância da dimensão do ambiente. Na análise que testou a QV geral como variável critério, a introdução da condição clínica no primeiro passo resultou em $R^{2}$ próximo a zero. No segundo passo, com a entrada das variáveis escolaridade e situação conjugal, verificou-se um aumento de $R^{2}$ da ordem de $7 \%$, com essas duas variáveis contribuindo com valores semelhantes de $\beta$, alcançando $9 \%$ de variância explicada da QV.

Tabela 1

Análises de Regressão Hierárquica (Passo 3) das Dimensões Psicossocial e Füsica da QV sobre as Variáveis Antecedentes (N=241)

\begin{tabular}{|c|c|c|c|c|}
\hline Variáveis & $\mathrm{B}$ & $\mathrm{B}$ & $F(g l)$ & Modelo Final \\
\hline Dimensão psicossocial & & & $\begin{array}{l}61,67 \text { *** } \\
(5,232)\end{array}$ & \\
\hline Condição clínica: assintomático & 0,02 & 0,02 & & \\
\hline Escolaridade & $-0,00$ & 0,01 & & \\
\hline Situação conjugal: vivendo com parceiro(a) & 0,14 & $0,12 * *$ & & $\mathrm{R}=0,78^{* * *}$ \\
\hline Enfrentamento no problema & 0,11 & $0,13^{* *}$ & & $R^{2}=0,61$ \\
\hline Enfrentamento na emoção & $-0,36$ & $\overline{0,41 * * *}$ & & $R^{2}$ ajustado $=0,59$ \\
\hline Busca de práticas religiosas & 0,04 & 0,07 & & $\Delta R^{2}=0,52$ \\
\hline Suporte social emocional & 0,31 & $0,43^{* * *}$ & & \\
\hline Suporte social instrumental & 0,01 & 0,01 & & \\
\hline Dimensão física & & & $\begin{array}{l}10,07 * * * \\
(5,232)\end{array}$ & \\
\hline Condição clínica: assintomático & 0,18 & $0,14^{*}$ & & \\
\hline Escolaridade & 0,03 & 0,10 & & \\
\hline Situação conjugal: vivendo com parceiro(a) & $-0,05$ & 0,05 & & $\mathrm{R}=0,49 * * *$ \\
\hline Enfrentamento no problema & $-0,01$ & $-0,02$ & & $R^{2}=0,24$ \\
\hline Enfrentamento na emoção & $-0,33$ & $\overline{0,37 * * *}$ & & $R^{2}$ ajustado $=0,22$ \\
\hline Busca de práticas religiosas & 0,02 & 0,04 & & $\Delta R^{2}=0,16$ \\
\hline Suporte social emocional & 0,08 & 0,11 & & \\
\hline Suporte social instrumental & 0,08 & 0,03 & & \\
\hline
\end{tabular}

Nota. ${ }^{*} p<0,05 ;{ }^{* *} p<0,01 ; * * * p<0,001$ 
Tabela 2

Análises de Regressão Hierárquica (Passo 3) das Dimensões do Ambiente e QV Geral sobre as Variáveis Antecedentes (N=241)

\begin{tabular}{|c|c|c|c|c|}
\hline Variáveis & $\mathrm{B}$ & $\mathrm{B}$ & $F(g l)$ & Modelo Final \\
\hline Dimensão do ambiente & & & $\begin{array}{l}23,82 \text { *** } \\
(5,232)\end{array}$ & \\
\hline Condição clínica: assintomático & 0,01 & 0,00 & & \\
\hline Escolaridade & 0,08 & $0,29 * * *$ & & \\
\hline Situação conjugal: vivendo com parceiro(a) & 0,03 & 0,03 & & $R=0,68^{* * *}$ \\
\hline Enfrentamento no problema & 0,00 & 0,06 & & $R^{2}=0,46$ \\
\hline Enfrentamento na emoção & $-0,18$ & $-0,23 * * *$ & & $R^{2}$ ajustado $=0,45$ \\
\hline Busca de práticas religiosas & $-0,03$ & $-0,06$ & & $\Delta \mathrm{R}^{2}=0,27$ \\
\hline Suporte social emocional & 0,12 & $0,17 * *$ & & \\
\hline Suporte social instrumental & 0,18 & $0,27 * * *$ & & \\
\hline Dimensão física & & & $\begin{array}{l}16,94 * * * \\
(5,232)\end{array}$ & \\
\hline Condição clínica: assintomático & 0,08 & 0,05 & & \\
\hline Escolaridade & 0,03 & 0,08 & & \\
\hline Situação conjugal: vivendo com parceiro(a) & 0,14 & 0,09 & & $\mathrm{R}=0,57^{* * *}$ \\
\hline Enfrentamento no problema & 0,13 & 0,12 & & $R^{2}=0,32$ \\
\hline Enfrentamento na emoção & $-0,28$ & $-0,24 * * *$ & & $R^{2}$ ajustado $=0,30$ \\
\hline Busca de práticas religiosas & 0,03 & 0,04 & & $\Delta R^{2}=0,25$ \\
\hline Suporte social emocional & 0,25 & $0,27^{* * *}$ & & \\
\hline Suporte social instrumental & 0,07 & 0,08 & & \\
\hline
\end{tabular}

Nota. $* p<0,05 ; * * p<0,01 ; * * * p<0,001$

No terceiro passo, as variáveis na equação levaram a um incremento de $25 \%$ do valor de $\mathrm{R}^{2}$. O modelo final, com $30 \%$ (ajustado) de variância explicada, teve duas variáveis significativas: suporte emocional e enfrentamento na emoção, esta última como preditor negativo (Tabela 2).

\section{Discussão}

Como esperado, as variáveis psicossociais contribuíram de modo significativo para a explicação das dimensões da QV das pessoas soropositivas que participaram do estudo. Também foi constatado o fraco poder de predição da variável condição clínica, que contribuiu como preditor significativo apenas no modelo final da dimensão fisica da QV. É possível supor que o tratamento anti-retroviral leve a quase indiferenciação quanto ao funcionamento físico, entre pessoas sintomáticas que estão em tratamento anti-retroviral - e recuperaram sua resposta imunológica e as condições de saúde física - e aquelas assintomáticas, cujos sinais e sintomas da AIDS ainda são inexistentes (Rabkin \& cols., 2000).

O maior percentual de variância explicada foi da dimensão psicossocial, com as variáveis antecedentes que entraram no modelo alcançando, em conjunto, maior poder de predição. Assim, os resultados permitem concluir que pessoas soropositivas que avaliaram maior disponibilidade e satisfação com o suporte emocional, que referiram menor utilização de estratégias de enfrentamento focalizado na emoção, maior freqüência de enfrentamento no problema e viviam com parceiro(a) relataram melhores condições de funcionamento das esferas cognitiva, afetiva e dos relacionamentos sociais, e maior satisfação com esses aspectos. Este achado é semelhante ao encontrado por Friedland e colaboradores (1996), levando à suposição de que escores mais altos na dimensão psicossocial da QV foram indicadores de bem-estar psicológico e de ajustamento à condição de soropositividade no presente estudo.

No caso da dimensão física como variável critério, os resultados mostraram que o modelo final foi composto por duas variáveis: condição clínica (assintomático) e enfrentamento focalizado na emoção, como preditor negativo. Somente nessa dimensão a condição clínica alcançou significância, sugerindo que pessoas assintomáticas avaliaram melhor o seu funcionamento físico. De fato, mesmo com a melhoria das condições de saúde devido à terapia anti-retroviral, em uso pela maioria dos participantes, é plausível supor que pessoas sintomáticas tenham mais intercorrências, desconforto ou debilidade física, o que não costuma ocorrer com aquelas que são assintomáticas (Oliveira \& cols., 1996). A entrada nesse modelo da variável enfrentamento na emoção mostrou que pessoas que utilizavam mais essa estratégia fizeram uma pior avaliação de suas condições físicas, resultado que pode ser atribuído à possibilidade dessa medida ter funcionado como um indicador de dificuldades psicológicas e emocionais, com repercussão negativa sobre a percepção do funcionamento físico. Resultados nessa direção já haviam sido encontrados por Revicki e colaboradores (1998) e por Fleck e colaboradores (1999), ao verificarem que medidas de depressão e sentimentos de desamparo estiveram associadas a piores escores na dimensão física da QV.

Os resultados do teste de modelo relativos à dimensão do ambiente mostraram as diferenças entre os participantes quanto 
à condição socioeconômica. A escolaridade foi, de fato, o mais forte preditor, apontando que pessoas com nível de escolaridade mais alto, e que relataram maior disponibilidade e satisfação com os suportes instrumental e emocional, e que referiram menos utilização do enfrentamento na emoção, tenderam a estimar melhores condições e a avaliar de modo mais favorável o ambiente onde viviam. O modelo que analisou a QV geral teve apenas duas variáveis preditoras: suporte emocional e enfrentamento na emoção (negativo), permitindo concluir que pessoas soropositivas que referiram melhor apreciação da qualidade de suas vidas relataram ter maior disponibilidade e estar mais satisfeitas com o suporte emocional e fazer menor uso de estratégias de enfrentamento focalizado na emoção. Evidencia-se aqui a necessidade da investigação de outras variáveis antecedentes em estudos futuros, dado o reduzido percentual de variância explicada encontrado, que permite supor a limitação das variáveis estudadas como preditores da QV geral.

A constatação de que os participantes utilizavam mais estratégias cognitivas e comportamentais direcionadas ao manejo do problema e menos estratégias focalizadas na emoção vem ao encontro de outros achados sobre enfrentamento em pessoas com HIV/AIDS (Friedland \& cols., 1996; Singh \& cols., 2000). Quanto ao enfrentamento focalizado na emoção, é possível inferir, como mencionado anteriormente, que a maior utilização dessa estratégia seria indicativa da presença de dificuldades emocionais associadas à soropositividade. Os conteúdos dos itens da EMEP, que mensuram essa modalidade de enfrentamento, descrevem sentimentos de culpa em relação a si mesmo e ao outro, emoções negativas, esquiva e pensamento fantasioso, o que leva a supor que escores mais elevados nessa estratégia seriam sugestivos de dificuldades psicológicas. Resultados nessa direção foram encontrados por pesquisadores que utilizaram outras medidas de enfrentamento (Schmitz \& Crystal, 2000). Um resultado obtido nas análises bivariadas - uso mais freqüente do enfrentamento focalizado na emoção por pessoas com escolaridade menor - permite supor que dificuldades relativas à condição socioeconômica somar-se-iam às dificuldades da condição de saúde resultando em um número maior de estressores, com repercussão negativa sobre o bem-estar psicológico e sobre a apreciação da QV, como foi verificado nos estudos de Cunningham e colaboradores (1995).

A variável busca de práticas religiosas foi a única que não alcançou significância nos modelos finais. No entanto, é digno de nota que alguns achados foram semelhantes aos encontrados em pesquisa com amostra brasileira não soropositiva, realizada por Seidl e colaboradores (2001), onde pessoas com escolaridade menor apresentaram maior uso dessa modalidade de enfrentamento. Destaca-se a necessidade de estudos que elucidem melhor o papel da religiosidade em situação de enfermidade crônica, principalmente devido ao significado das tradições religiosas na sociedade brasileira (Biggar \& cols., 1999).

O suporte social teve sua importância destacada a partir do peso que alcançou como variável preditora nas diferentes dimensões da QV, em especial o suporte emocional, junto a pessoas acometidas por enfermidade ainda marcada pelo preconceito. No entanto, observou-se o relato de maior disponibilidade e maior satisfação com os suportes instrumental e emocional, por aquelas que viviam com parceiro(a), um resultado que confirma evidências da literatura sobre suporte social (Ingram, Jones, Fass, Neidig \& Song, 1999; Schmitz \& Crystal, 2000). A maior disponibilidade percebida e satisfação com o suporte instrumental de pessoas casadas e/ou em união consensual parece decorrer do fato de que essa modalidade de suporte implica o apoio em questões domésticas e operacionais do tratamento, o que é facilitado pela proximidade espacial entre o provedor e o recebedor do suporte. Um resultado que chamou a atenção foi o relato de menor disponibilidade e satisfação com o suporte emocional por participantes com baixa escolaridade, embora não houvesse diferença quanto ao suporte instrumental. Aspectos socioeconômicos podem estar aqui implicados: eventualmente em função de maior preconceito junto a segmentos menos escolarizados da população, essas pessoas poderiam estar com mais dificuldade de receber apoio emocional. Pode-se presumir, ainda, que níveis mais altos de escolaridade estariam favorecendo as habilidades sociais e de comunicação, levando a condições facilitadoras da busca e da satisfação com o suporte emocional.

No que concerne às facetas da QV que indicaram a presença de maiores dificuldades e insatisfação, duas delas compõem a dimensão do ambiente e parecem refletir o impacto da condição socioeconômica: recursos financeiros e segurança física e proteção. A dependência de medicação e tratamento, faceta da dimensão física, refere-se à percepção de que o prazo indefinido do tratamento e a perspectiva de cronicidade levam a uma situação de uso permanente da medicação. A presença de sentimentos negativos pode ser atribuída a dificuldades emocionais associadas à soropositividade, podendo configurar quadros de depressão ou de ansiedade, com diferentes níveis de gravidade (Khouzam, Donnelly \& Ibrahim, 1998). Por fim, a repercussão negativa da soropositividade - enfermidade sexualmente transmissível - sobre a vida sexual e sobre a conjugalidade, justificam os escores mais baixos nessa esfera.

Há limitações deste estudo que sugerem cautela na conclusão sobre as medidas sociodemográficas. O nível de escolaridade pode ser insuficiente para medir condição social e econômica. Em estudos futuros sugere-se inclusão de outros indicadores (Ex.: renda familiar, acesso a bens e serviços), buscando melhor compreensão dessas relações. Da mesma forma, a situação conjugal foi medida por um indicador restrito. A informação sobre viver ou não com parceiro(a) pode ter excluído informação relevante sobre ocorrência de relacionamento amoroso e sexual na vida da pessoa. A existência de uma parceria afetiva-sexual significativa poderia ser uma informação mais abrangente e válida, como avaliado por Singh e colaboradores (1999).

O presente estudo é pioneiro na investigação de preditores da QV em amostra de pessoas soropositivas brasileiras, com base em teste de modelo. Os achados apontam para a relevância de estudos futuros com utilização de técnicas que permitam testes simultâneos de relações entre variáveis mediadoras e moderadoras (Ex.: as 
equações estruturais), mais adequados para fenômenos complexos multidimensionais.

A pesquisa tem implicações para a prática profissional, com a constatação da importância de apreender, compreender e atender as demandas dos usuários dos serviços, visando a encaminhar ações direcionadas para a sua resolubilidade e fortalecimento do vínculo do paciente com a equipe de saúde. O caráter de cronicidade da AIDS prevê o seguimento dos pacientes a longo prazo. Isto acarreta a necessidade de avaliação e acompanhamento dos aspectos psicossociais, tais como as variáveis analisadas no presente estudo. Assim, será possível subsidiar continuamente a estruturação dos serviços para atender a novas demandas médicas e psicossociais que possam surgir no contexto de vida de pessoas soropositivas, visando à integralidade e à melhor qualidade da atenção em saúde.

\section{Referências}

Barroso, J. (1997). Reconstructing my life: Becoming a long-term survivor of AIDS. Qualitative Health Research, 7, 57-74.

Biggar, H., Forehand, R., Devine, D., Brody, G., Armistead, L., Morse, E. \& Simon, P. (1999). Women who are HIV infected: The role of religious activity in psychosocial adjustment. Aids Care, 11, 195-199.

Clark, K. A., Bormann, C. A., Cropanzamo, R. S. \& James, K. (1995). Validation evidence for three coping measures. Journal of Personalty Assessment, 65, 434455.

Cunningham, W. E., Hays, R. D., Williams, K. W., Beck, K. C., Dixon, W. J. \& Shapiro, M. F. (1995). Acess to medical care and helth-related quality of life for low-income persons with symptomatic human immunodeficiency virus. Medical Care, 33, 739-754.

Dunbar, H. T., Mueller, C. W., Medina, C. \& Wolf, T. (1998). Psychological and spiritual growth in women living with HIV. Social Work, 43, 144-154.

Fleck, M. P., Louzada, S., Xavier, M., Cachamovich, E., Vieira, G, Santos, L. \& Pinzon, V. (1999). Aplicação da versão em português do instrumento de avaliação de qualidade de vida da Organização Mundial da Saúde (WHOQoL100). Revista de Saúde Pública, 33, 198-205.

Friedland, J., Renwick, R. \& McColl, M. (1996). Coping and social support as determinats of quality of life in HIV/AIDS. AIDS Care, 8, 15-31.

Gimenes, M. M. G. \& Queiroz, B. (1997). As diferentes fases do enfrentamento durante o primeiro ano após a mastectomia. Em M. G. G. Gimenes \& M. H. Fávero (Orgs), A mulher e o cancer (pp. 171-195). Campinas, SP: Psy.

Green, G. (1993). Editorial review: Social support and HIV. AIDS Care, 5, 87-104.

Ingram, K. M., Jones, D. A., Fass, R. J., Neidig, J. L. \& Song, Y. S. (1999). Social support, and unsupportive social interactions: Their association with depression among people living with HIV. Aids Care, 11, 313-329.

Khouzam, H. R., Donnelly, N. J. \& Ibrahim, N. F. (1998). Psychiatric morbidity in HIV patients. Canadian Journal of Psycbiatry, 43, 51-56.

Leserman, J., Petitto, J. M., Golden, R. N., Gaynes, B. N., Gu, H., Perkins, D. O., Silva, S. G., Folds, J. D. \& Evans, D. L. (2000). Impact of stressful life events, depression, social support, coping and cortisol on progression to AIDS. American Journal of Psychiatry, 157, 1221-1228.
Ministério da Saúde - Programa Nacional de DST e Aids (2003). Aids - Boletim Epidemiológico. Ano XVII n ${ }^{o} 01-1^{\text {a a }} 52^{\mathrm{a}}$ semanas epidemiológicas, janeiro a dezembro de 2003.

Oliveira, M. S., Mello e Silva, A. C. C., Atomyla, A. N., Bonasser Filho, F. \& Geraldes, S. M. (1996). Aspectos clínicos e tratamentos específicos. Em A. L. M. Lima, C. R. Kiffer \& D. Uip (Orgs.), HIV/AIDS: Perguntas e respostas (pp. 93-126). São Paulo: Atheneu.

Power, M., Bullinger, M. \& Harper, A. (1999). The World Health Organization WHO-QoL-100 tests of the universality of quality of life in 15 different cultures groups worldwide. Health Psychology, 18, 495-505.

Rabkin, G. J., Ferrando, S., Lin, S. H., Sewell, M. \& McElhiney, M. (2000). Psychological effects of HAART: A 2-year study. Psychosomatic Medicine, 62, 413-422.

Renwick, R., Halpen, T., Rudman, D. \& Friedland, J. (1999). Description and validation of a measure of received support specific to HIV. Psychological Reports, 84, 663- 673.

Revicki, D. A., Sorensen, S. \& Wu, A. W. (1998). Reliability and validity of physical and mental health summary scores from the medical outcomes study HIV health survey. Medical Care, 36, 126-137.

Rosenfeld, B., Breitbart, W., McDonald, M. V., Passik, S. D., Thaler, H. \& Portenoy, R. K. (1996). Pain in ambulatory AIDS patientes: Impact of pain on psychological functioning and quality of life. Pain, 68, 323-328.

Schmitz, M. F. \& Crystal, S. (2000). Social relations, coping, and psychological distress among persons with HIV/AIDS. Journal of Applied Social Psychology, 30, 665-685.

Seidl, E. M. F., Tróccoli, B. T. \& Zannon, C. M. L. C. (2001). Análise fatorial de uma medida de estratégias de enfrentamento. Psicologia: Teoria e Pesquisa, 17, 225234.

Seidl, E. M. F. \& Zannon, C. M. L. C. (2004). Qualidade de vida e saúde: Aspectos conceituais e metodológicos. Cadernos de Saúde Pública, 20, 580-588.

Singh, N., Berman, S. M., Swindells, S., Justis, J. C., Mohr, J. A., Squier, C. \& Wagener, M. M. (1999). Adherence of Human Immunodeficiency Virusinfected patients to antiretroviral therapy. Clinical Infectious Diseases, 29, 824830.

Smith, K. W., Avis, N. E., Mayer, K. H. \& Swislow, L. (1997). Use of the MQoLHIV with assymptomatic HIV-positive patients. Quality of Life Research, 6, 555-560.

Sowell, R. L., Seals, B. F., Moneyham, L., Demi, A., Cohen, L. \& Brake, S. (1997). Quality of life in infected women in the south-eastern United States. AIDS Care, 9, 501-512.

Tabachnick, G. B. \& Fidell, L. S. (1996). Using multivariate statistics. New York: HarperCollins.

The WHOQoL Group (1998). The World Health Organization quality of life assessment (WHOQoL): Development and general psychometric properties. Social Science and Medicine, 46, 1569-1585.

Vitaliano, P. P., Russo, J., Carr, J. E., Maiuro, R. D. \& Becker, J. (1985). The ways of Coping Checklist: Revision and psychometric properties. Multivariate Behavioral Research, 20, 3-26.

Wu, A. W. (2000). Quality of life assessment comes of age in the era of highly active antiretroviral therapy. AIDS, 14, 1449-1451.

Recebido: 17/03/2004

Última Revisão: 06/10/2004

Aceite Final: 22/11/2004

Sobre os autores

Eliane Maria Fleury Seidl é Doutora em Psicologia pela Universidade de Brasília, Professora Adjunta do Instituto de Psicologia da Universidade de Brasilia.

Célia Maria Lana da Costa Zannon é Doutora em Psicologia Experimental pela Universidade de São Paulo, Professora aposentada e Pesquisadora Associada Adjunta do Instituto de Psicologia da Universidade de Brasília.

Bartholomeu Torres Tróccoli é Doutor em Personalidade e Psicologia Social pela Universidade de Wiscosin-Madison, EUA, Professor Adjunto do Instituto de Psicologia da Universidade de Brasília. 